\title{
Consecutive TMS-fMRI Reveals an Inverse Relationship in BOLD Signal between Object and Scene Processing
}

\author{
Caitlin R. Mullin and Jennifer K. E. Steeves \\ Centre for Vision Research and Department of Psychology, York University, Toronto, Ontario M3J 1P3, Canada
}

The human visual system is capable of recognizing an infinite number of scenes containing an abundance of rich visual information. There are several cortical regions associated with the representation of a scene, including those specialized for object processing (the lateral occipital area [LO]) and for the spatial layout of scenes (the parahippocampal place area). Although behavioral studies have demonstrated that these image categories (scenes and objects) exert an influence on each other such that scene context can facilitate object identification or that scene categorization can be impaired by the presence of a salient object, little is known about the apparent cortical interactions involved in building the conscious representation of a complete scene. It has been shown that transcranial magnetic stimulation (TMS) to the left LO disrupts object categorization but facilitates scene categorization. Here, we show that this effect is also reflected by changes in the BOLD signal such that TMS to the left LO decreases BOLD signal at the stimulation site (LO) while viewing objects and increases BOLD signal in the left PPA when viewing scenes. This suggests that these regions, although likely not on a strict hierarchy of bottom-up coding, share functional communication likely in the form of inhibitory connections.

Key words: LO; PPA; TMS; fMRI; scene processing; object processing

\section{Introduction}

The ventral visual cortex contains specialized regions or "modules" for specific visual categories (for review, see Grill-Spector and Malach, 2004). It has become increasingly clear, however, that visual representations are not solely the result of processing in isolated cortical regions, but rather are produced by a network of connectivity between several brain areas. Therefore, rather than focusing on simply characterizing the properties of individual brain regions, the goal of neuroscience research has shifted to characterizing interactions and connectivity between brain regions.

Real-world scenes are tremendously complex stimuli containing several different sources of information, including edges, surfaces, textures, local objects, and spatial layout. Given their richness, it is not surprising that neuroimaging has revealed a network of cortical regions in ventral visual cortex selective to scene images, including those selective to both objects (e.g., the lateral occipital region [LO]; Malach et al., 1995) and scene spatial layout (e.g., the parahippocampal place area [PPA]; Epstein and Kanwisher, 1998). How do these anatomically distinct regions contribute to scene processing and what connections do they share?

Early theories of scene processing emphasized an objectcentered approach in which objects must first be perceived to

Received June 15, 2013; revised 0ct. 27, 2013; accepted 0ct. 29, 2013.

Author contributions: C.R.M. and J.K.E.S. designed research; C.R.M. performed research; C.R.M. analyzed data; C.R.M. and J.K.E.S. wrote the paper.

This work was supported by the Natural Sciences and Engineering Research Council of Canada and the Canada Foundation for Innovation (to J.K.E.S.). We thank Krista Kelly for assistance with neuroimaging analysis.

Correspondence should be addressed to Jennifer Steeves, Centre for Vision Research, 1032 Sherman Health Science Research Centre, York University, Toronto, Ontario M3J 1P3, Canada. E-mail: steeves@yorku.ca.

DOI:10.1523/JNEUROSCI.2537-13.2013

Copyright $\odot 2013$ the authors $\quad 0270-6474 / 13 / 3319243-07 \$ 15.00 / 0$ activate a scene schema to achieve accurate scene recognition (Friedman, 1979; Biederman, 1981, 1987; De Graef et al., 1990). This approach suggests that scenes are processed hierarchically, building upon the initial identification of prominent objects. However, scene categorization can take place without intact object processing, as evidenced by a patient with object agnosia who was nonetheless able to categorize scenes (Steeves et al., 2004). This demonstrates that scenes are not processed on a singular bottom-up hierarchy, but rather object and scene information are likely processed on separate parallel pathways.

Although these pathways may be independent, it is likely that they share interactive connections. Several studies have demonstrated that altering the perception of objects can lead to changes in overall scene perception. For example, decreasing the availability of "signature" objects within the scene through masking decreases the ability to accurately categorize the scene (MacEvoy and Epstein, 2011). In addition, disruption of object processing through repetitive transcranial magnetic stimulation (rTMS) to area LO results in a minor facilitation in scene categorization (Mullin and Steeves, 2011).

Given that the effects of TMS have been shown to propagate beyond the site of stimulation (Ruff et al., 2009; Siebner et al., 2009; Ferreri et al., 2011), it has become a powerful tool for measuring brain connectivity when paired with neuroimaging. In the present study, we used the "perturb-and-measure" method (Siebner et al., 2009), which combines offline rTMS with functional magnetic resonance imaging (fMRI) to investigate the BOLD signal changes evoked by rTMS. We stimulate object selective cortex (left LO) and examine BOLD signal in both $\mathrm{LO}$ and remote scene selective areas (PPA and others). This method allows assessment of functional connections between cortical regions based on the idea that any changes in activity at remote 
regions (i.e., scene areas) after stimulation to object selective cortex indicate a causal and functional relationship between these regions.

\section{Materials and Methods}

Participants. Nine healthy volunteers ( 5 men, aged $24-41$ years, mean 30.6 years) participated in all conditions of the experiment. All participants were in good health with normal or corrected-to-normal vision and, according to self-report, had no known contraindications to rTMS or fMRI. All participants had previous experience participating in rTMS and fMRI measurements. Informed consent was obtained and the experiment was conducted in accordance with the York University Office of Research Ethics, which follows the guidelines outlined by the Declaration of Helsinki.

Experimental design overview. The perturb-and-measure method of combining offline rTMS with fMRI consists of three stages: (1) prestimulation $\mathrm{fMRI}$ to functionally localize stimulation sites and regions of interest (ROIs), (2) the application of rTMS to functionally defined ROIs or control sites on separate days, and (3) poststimulation fMRI to assess rTMS related changes in BOLD signal.

Image acquisition and preprocessing. All structural and functional images in the pre- and poststimulation scanning sessions were acquired using a 3 tesla Siemens Magnetom Tim Trio magnetic resonance scanner at York University's Sherman Health Sciences Research Centre (Toronto, Canada). Structural images were acquired with a T1 MPRAGE imaging sequence (in-plane resolution $=2 \times 2 \mathrm{~mm}$, imaging matrix $=122 \times 122, \mathrm{TR}=8300 \mathrm{~ms}, \mathrm{TE}=100 \mathrm{~ms}$, flip angle $=90^{\circ}$, FoV $=24 \times 24 \mathrm{~cm}$ ), recording 176 slices at a slice thickness of $2 \mathrm{~mm}$. Stimulation sites and ROIs for subsequent comparisons across stimulation conditions were localized using fMRI. Functional volumes were acquired using a Siemens 32 channel high-resolution brain array coil. Functional images were acquired with echoplanar imaging with a T1weighted sequence of 32 contiguous axial slices (in-plane resolution $=$ $2.5 \times 2.5 \mathrm{~mm}$, slice thickness $=3 \mathrm{~mm}$, imaging matrix $96 \times 96, \mathrm{TR}=$ $2000 \mathrm{~ms}, \mathrm{TE}=30 \mathrm{~ms}$, flip angle $\left.=90^{\circ}, \mathrm{FOV}=24 \times 24 \mathrm{~cm}\right)$.

All imaging analyses were performed using BrainVoyager QX (Brain Innovation). Functional data were subject to several preprocessing steps, including linear trend removal to exclude scanner-related signal drift, high-pass filtering to remove temporal frequencies lower than three cycles/run, and a correction for small interscan head movements using a rigid body algorithm rotating and translating each functional volume in 3D space. Each participant's functional images were coregistered with their anatomical images. The functional data were analyzed using a general linear model.

Prestimulation $f M R I$. Functional images from an independent localizer were acquired before the onset of the main experiment and served two functions: (1) to functionally localize the stimulation site in each participant and (2) to independently identify ROIs for examination subsequent to each of the three stimulation conditions.

The localizer paradigm was comprised of images from three different image categories, objects, scenes, and faces, and used repetition detection to maintain attention. Each run began and finished with a fixation cross for $16 \mathrm{~s}$. Six repetitions of three $16 \mathrm{~s}$ blocks of the three categories of stimuli were presented in a pseudorandom order with $16 \mathrm{~s}$ of fixation between each repetition. Each block contained 16 stimuli presented for one second each. Each run lasted $6 \mathrm{~min} 52 \mathrm{~s}$ and was repeated twice. Stimuli were presented with a rear-projection system (Avotec).

To determine the rTMS target stimulation site, a linear balanced contrast of objects versus faces and scenes was used based on successful localization from previous experiments (Mullin and Steeves, 2011). The target site was individually identified in each participant by determining the peak object-selective activation in the lateral occipital region of the left hemisphere (Table 1). Stimulation was restricted to the left hemisphere because our research group has previously demonstrated stronger modulation of behavioral object and scene categorization with rTMS to the left LO compared with the right (Mullin and Steeves, 2011). In addition, the left hemisphere has shown a stronger object selective response in previous studies (Sergent et al., 1992) and in our current participants.
Table 1. Mean Talairach coordinates for each of the centers of gravity of the ROls across participants

\begin{tabular}{|c|c|c|c|c|c|}
\hline \multirow[b]{2}{*}{ Functional ROI } & \multirow{2}{*}{$\begin{array}{l}\text { Participants with } \\
\text { identified region } \\
\text { (of } 9 \text { total) }\end{array}$} & \multirow{2}{*}{$\begin{array}{l}\text { Mean cluster } \\
\text { size, } \mathrm{mm}^{3}\end{array}$} & \multicolumn{3}{|c|}{$\begin{array}{l}\text { Mean Talairach } \\
\text { coordinates, mean (SD) }\end{array}$} \\
\hline & & & $x$ & $y$ & $z$ \\
\hline \multicolumn{6}{|c|}{ Object-selective regions } \\
\hline Left LO* & 9 & 350 & $-38(9)$ & $-75(10)$ & $-13(11)$ \\
\hline Right LO & 9 & 309 & $40(3)$ & $-75(4)$ & $-13(8)$ \\
\hline \multicolumn{6}{|c|}{ Scene-selective regions } \\
\hline Left PPA & 9 & 365 & $-24(11)$ & $-46(9)$ & $-13(9)$ \\
\hline Right PPA & 9 & 351 & $23(4)$ & $-48(8)$ & $-12(9)$ \\
\hline Left TOS & 8 & 286 & $-28(6)$ & $-88(4)$ & $10(11)$ \\
\hline Right TOS & 8 & 292 & $33(5)$ & $-83(10)$ & $9(9)$ \\
\hline \multicolumn{6}{|c|}{ Face-selective regions } \\
\hline Left OFA & 8 & 279 & $-37(3)$ & $-74(9)$ & $-18(6)$ \\
\hline Right OFA & 9 & 319 & $39(8)$ & $-73(9)$ & $-15(9)$ \\
\hline Left FFA & 7 & 297 & $-38(4)$ & $-48(9)$ & $-20(8)$ \\
\hline Right FFA & 9 & 406 & $39(4)$ & $-46(3)$ & $-19(10)$ \\
\hline
\end{tabular}

Each region was identified with a threshold of $p<0.05$, Bonferroni corrected.

*Stimulation site.

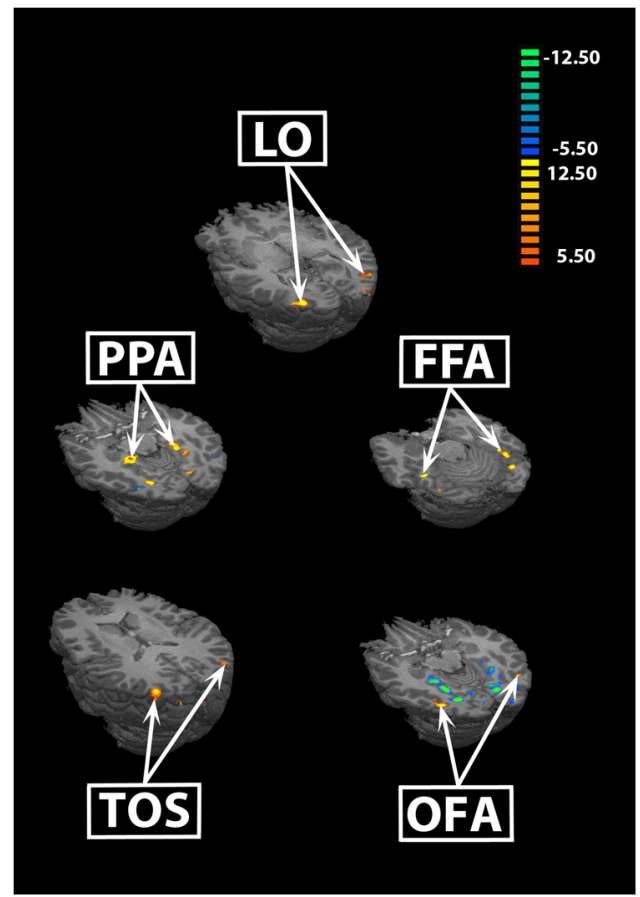

Figure 1. ROIs (LO, PPA, TOS, FFA, and OFA) as shown on a representative participant's brain.

Once the individual stimulation sites were acquired, they were localized on the head of each participant with Brainsight image-guided coregistration software and hardware (Rogue Research) using individual structural and functional scans. Common reference points on both the MRI images and the participant's head were selected to create a coregistration matrix. The spatial relationship between these reference points on the MRI images and those on the participant's head were coregistered using a Polaris infrared marker system.

In addition, the data obtained from the pre-rTMS localizer were used to create independent ROIs (see Fig. 1 for each of the image categories to examine signal changes subsequent to the three stimulation conditions [rTMS to left LO, sham rTMS to left LO, and rTMS to vertex]). A linear balanced contrast of objects versus faces and scenes was used to localize the ROI for area LO (also our stimulation site in the left hemisphere). A similar contrast of scenes versus objects and faces was used to identify ROIs for scene-selective regions, the PPA and the transverse occipital sulcus (TOS) [Note: The occipitotemporal scene processing network also typically includes activation within the retrosplenial cortex; however, this 
region could not be reliably identified in the majority of participants during the independent localizer. Therefore, the scene-selective ROIs were restricted to the PPA and TOS.] For each ROI identified in the stimulated hemisphere, its contralateral counterpart was also defined. Evaluation of the contralateral ROIs allowed the assessment of potential remote interhemispheric effects.

ROIs were also created for two cortical areas selective for face images. These regions were defined using a linear balanced contrast of isolated faces versus objects and scenes and corresponded to the well known occipital face area (OFA; Gauthier et al., 2000) and fusiform face area (FFA; Kanwisher et al., 1997) bilaterally (Table 1).

Transcranial magnetic stimulation. A Magstim Rapid ${ }^{2}$ Stimulator (Magstim) and a figure-of-eight coil with a diameter of $70 \mathrm{~mm}$ was used to deliver the stimulation pulses. The coil was held tangentially to the scalp surface with the handle pointed downward. The experimental design consisted of three stimulation conditions: (1) rTMS to left LO, (2) sham rTMS to left LO, and (3) rTMS to the vertex. The vertex, a point at the center of the top of the head, is defined as a point midway between the inion and the nasion and equidistant from the left and right intertragal notches. Stimulation at this location controls for potential nonspecific effects of rTMS to the brain, as well as the auditory and sensory artifacts (i.e., clicking sounds and tapping sensations on the scalp). Sham stimulation involved placing the coil at the left LO but positioning it orthogonal to the scalp surface so that no pulse entered the brain. Each stimulation condition was targeted in separate blocks and the order of the blocks was counterbalanced across participants.

A low-frequency pulse $(1 \mathrm{~Hz})$ was delivered at $60 \%$ of maximum stimulator output for $15 \mathrm{~min}$ (900 pulses), thereby providing $\sim 7.5 \mathrm{~min}$ of TMS-induced neural noise (Chen et al., 1997; Pascual-Leone et al., 1998) in which to assess the effects of the stimulation condition on the BOLD signal change. A steady intensity of the rTMS stimulator $(60 \%)$ was chosen based on behavioral effects previously observed in our research group at that intensity (Mullin and Steeves, 2011), as well as similar findings from other studies (Campana et al., 2002; Silvanto et al., 2005; Pitcher et al., 2007; Pitcher et al., 2009). The frequency, intensity, and duration of the rTMS train were within the safety limits of stimulation (Wassermann, 1998; Rossi et al., 2009). Earplugs were worn to reduce the noise associated with rTMS coil discharge. None of the participants reported any side effects of the experiment apart from slight head discomfort due to pressure from the rTMS coil.

Poststimulation fMRI and analysis. Upon completion of each of the three rTMS conditions, participants were taken directly to the scanner. To minimize the time between the offset of the rTMS and the onset of the fMRI, all rTMS sessions were performed in the MRI control room just outside of the five gauss line. Once the participant was positioned in the scanner, the functional localizer for objects, scenes, and faces (described above) was run once, followed by the acquisition of structural images. Scanning parameters in the poststimulation fMRI were identical to those in the prestimulation localizer, but only one functional run was performed due to time constraints of the rTMS effects.

BOLD response after each rTMS condition was examined by applying the prestimulation independent localizer ROIs to the coregistered poststimulation data for each participant. Thresholds were held constant across pre- and poststimulation conditions for each region. Using the volume-of-interest analysis tool in BrainVoyager QX software (Brain Innovation), a general linear model analysis was performed and peak percent BOLD signal (the mean of the three highest points in the eventrelated average signal) in these ROIs were determined for each stimulation condition. The results of these hypothesis-driven analyses are all reported at a Bonferroni-corrected threshold of $p<0.05$. Repeatedmeasures ANOVA compared percent BOLD signal across each stimulation condition.

Behavioral correlation. To consider whether any observed change in BOLD activity is reflected in a change in behavior, we correlated the behavioral results of participants who also partook in a previous rTMS experiment (Mullin and Steeves, 2011) that used the same stimulation parameters as the current experiment with the BOLD activity in the current experiment. Four subjects participated in both the behavioral rTMS study (Mullin and Steeves, 2011) and the current experiment (2 men, age 28-41 years). Mullin and Steeves (2011) provides complete experimental details. In brief, participants were instructed to categorize greyscale photographs of objects and scenes as either "natural" (e.g., a leaf or a beach scene) or "manmade" (e.g., a spoon or an airport scene) as quickly as possible without sacrificing accuracy. Object stimuli were taken from The Bank of Standardized Stimuli (BOSS; Brodeur et al., 2010) and scenes were from a photo image library (also used in Steeves et al., 2004). On each trial, a fixation cross appeared for $500 \mathrm{~ms}$ at the center of the display, followed by a stimulus image for $100 \mathrm{~ms}$, followed immediately by a mask consisting of static noise pattern that remained on the screen until participants responded.

Before the behavioral task, rTMS was delivered at low frequency $(1 \mathrm{~Hz})$ at $60 \%$ of maximal stimulator output for a total of 420 pulses $(7 \mathrm{~min})$.

\section{Results}

Independent ROIs for each of the three image categories were identified by $t$ tests $(p<0.025$ to $p<0.0005$, corrected for multiple comparisons using a Bonferroni correction, Brain Voyager, $q<0.05)$ for each participant. Talairach coordinates of the a priori-defined ROIs are shown in Table 1 . These coordinates corresponded well with those reported in the literature (LO: Grill-Spector et al., 2001; PPA and TOS: Golomb et al., 2011; OFA and FFA: Kanwisher et al., 1997; Steeves et al., 2006).

Event-related time courses corresponding to percent BOLD signal response associated with a specific image category were extracted from each ROI separately for each participant under each TMS condition. A repeated-measures ANOVA of image category (faces, scenes, objects), by TMS condition (TMS to LO, sham, and vertex) was performed on the peak BOLD signal change with appropriate post hoc comparisons for each ROI. Significant main effects of image category were expected for each ROI because contrasts typically reveal selective preferences for these specific image categories. Main effects of stimulation condition would indicate that TMS affected all image categories. A significant interaction would demonstrate that certain TMS conditions affect specific image categories more than others.

\section{Local effects of rTMS: object-selective ROI}

Within the left LO region and using a contrast selective for objects (objects $>$ [scenes + faces]), a $3 \times 3$ ANOVA of mean peak BOLD response for image category-by-stimulation condition revealed a main effect of image category $\left(F_{(2,16)}=28.889, p<\right.$ $0.001)$, no main effect of stimulation condition $\left(F_{(2,16)}=1.983\right.$, $p=0.170)$, but showed a significant interaction $\left(F_{(4,32)}=4.337\right.$, $p=0.006)$. False discovery rate (FDR)-corrected post hoc analysis revealed that during TMS to left $\mathrm{LO}$, BOLD signal response related to object perception $(\mathrm{M}=0.651, \mathrm{SD}=0.477)$ decreased significantly compared with that for the sham $(\mathrm{M}=1.120, \mathrm{SD}=$ $\left.0.247, t_{8}=3.211, p=0.036\right)$ and the vertex $(\mathrm{M}=1.006, \mathrm{SD}=$ $\left.0.229, t_{8}=-2.751, p=0.038\right)$ conditions. No significant differences were observed between the sham and vertex conditions $\left(t_{8}=1.605, p=0.149\right.$; Figs. 2, 3).

The BOLD signal activity for the nonpreferred image categories in left $\mathrm{LO}$ revealed no significant effects across stimulation conditions for both scenes (TMS to LO: $\mathrm{M}=0.256, \mathrm{SD}=0.364$ vs sham: $\mathrm{M}=0.117, \mathrm{SD}=0.207, t_{8}=-1.045, p=0.546$; TMS to LO vs vertex: $\mathrm{M}=0.121, \mathrm{SD}=0.247, t_{8}=0.957, p=0.546$; sham vs vertex: $t_{8}=-0.057, p=0.954$ ) and faces (TMS to LO: $\mathrm{M}=$ $0.051, \mathrm{SD}=0.298$ vs sham: $\mathrm{M}=0.061, \mathrm{SD}=0.239, t_{8}=0.952$, $p=0.925$; TMS to LO vs vertex: $\mathrm{M}=0.088, \mathrm{SD}=0.361, t_{8}=$ $0.623, p=0.556$; sham vs vertex: $t_{8}=0.275, p=0.787$ ).

\section{Remote effects of rTMS: scene-selective ROIs}

Using a contrast selective for scenes (scenes $>$ [objects + faces]), in the left PPA, a $3 \times 3$ ANOVA of mean peak BOLD response for 
image category-by-stimulation condition revealed a significant main effect of image category $\left(F_{(2,16)}=82.900, p<0.001\right)$, a significant main effect of stimulation condition $\left(F_{(2,16)}=7.211, p=0.006\right)$, and a significant interaction $\left(F_{(4,32)}=4.771\right.$, $p=0.004)$. FDR-corrected post hoc analysis revealed that during TMS to left LO $(\mathrm{M}=1.724, \mathrm{SD}=0.570)$, activity related to scene perception significantly increased compared with the sham $(\mathrm{M}=1.344$, $\left.\mathrm{SD}=0.404, t_{8}=4.222, p=0.005\right)$ and the vertex $\left(\mathrm{M}=1.498, \mathrm{SD}=5.22, t_{8}=7.031\right.$ $p=0.003)$ conditions. No significant differences were observed between the sham and vertex conditions $\left(t_{8}=-1.925, p=\right.$ 0.091; Figs. 2, 3). Analysis of the nonpreferred stimulus activity in left PPA revealed no significant effects of stimulation conditions for both objects (TMS to LO: $\mathrm{M}=0.312, \mathrm{SD}=0.246$ vs sham: $\mathrm{M}=$ $0.352, \mathrm{SD}=0.216, t_{8}=-0.634, p=$ 0.547 ; TMS to $\mathrm{LO}$ vs vertex: $\mathrm{M}=0.478$, $\mathrm{SD}=0.214, t_{8}=-1.930, p=0.195$; sham vs vertex: $\left.t_{8}=-1.680, p=0.195\right)$ and faces (TMS to LO: $\mathrm{M}=-0.430, \mathrm{SD}=$ 0.278 vs sham: $\mathrm{M}=-0.665, \mathrm{SD}=0.241$, $t_{8}=1.715, p=0.187$; TMS to LO vs vertex: $\mathrm{M}=-0.656, \mathrm{SD}=0.256, t_{8}=2.292$ $p=0.156$; sham vs vertex: $t_{8}=-0.112$, $p=0.910$; Figs. 2, 3).

A $3 \times 3$ ANOVA of mean peak BOLD response within the scene selective region in the left TOS showed a significant main effect of image category $\left(F_{(2,16)}=96.922\right.$, $p<0.001)$ but no main effect of stimulation condition $\left(F_{(2,16)}=0.451, p=0.646\right)$ and no interaction between image category and stimulation condition $\left(F_{(4,24)}=\right.$ $0.384, p=0.635$ ).

\section{Remote effects of rTMS: face-selective ROIs}

To determine whether the effects of stimulation to left LO are propagated outside of scene- and object-processing regions, we evaluate changes in BOLD response in the face-selective left OFA and left FFA. Repeated-measures ANOVAs revealed a significant main effect of image category for the left OFA $\left(F_{(2,28)}=12.139, p=0.001\right)$ and left FFA $\left(F_{(2,24)}=16.238, p>0.001\right)$, demonstrating the selectivity of these regions for faces over objects and scenes. No significant main effects for stimulation condition or interactions between the image categories and stimulation condition were observed for either the left OFA $\left(F_{(2,28)}=0.314, p=0.736, F_{(2,28)}\right.$ $=0.384, p>0.818)$ or the left FFA $\left(F_{(2,24)}=1.205, p=0.334\right.$, $\left.F_{(2,24)}=1.257, p>0.314\right)$.

Effects of rTMS in hemisphere contralateral to stimulation Although interhemispheric effects of TMS have been demonstrated previously with BOLD signal (Bestmann et al., 2008; Blankenburg et al., 2008), the right hemisphere (contralateral to stimulation) showed no significant main effect of stimulation condition and no interaction between image category and stim- ulation conditions within the right $\mathrm{LO}\left(F_{(2,16)}=0.254, p=0.137\right.$, $\left.F_{(4,32)}=0.235, p=0.080\right)$, the right $\mathrm{PPA}\left(F_{(2,16)}=0.168, p=\right.$ $\left.0.847, F_{(4,32)}=2.475, p=0.091\right)$, or the right TOS $\left(F_{(2,16)}=\right.$ $\left.1.759, p=0.280, F_{(4,32)}=1.420, p=0.253\right)$. The face-selective ROIs in the right hemisphere also showed no main effect of stimulation condition or interaction (right OFA: $F_{(2,16)}=0.443, p=$ $0.649, F_{(4,32)}=2.637, p=0.087$; right FFA: $F_{(2,16)}=1.524, p=$ $\left.0.248, F_{(4,32)}=1.081, p=0.382\right)$.

\section{Comparison of BOLD signal and behavioral performance}

We compared the current effects of rTMS at the cortical level with behavioral measures from a previous study that used the same rTMS protocol as in the current experiment in a subset of four participants who took part in both experiments (Mullin and Steeves, 2011, Experiment 1). A Pearson's correlation between the BOLD response in the object-selective left $\mathrm{LO}$ and behavioral performance on the object categorization task at the threestimulation conditions (sham rTMS to left LO, rTMS to vertex, 


\section{Left Hemisphere}
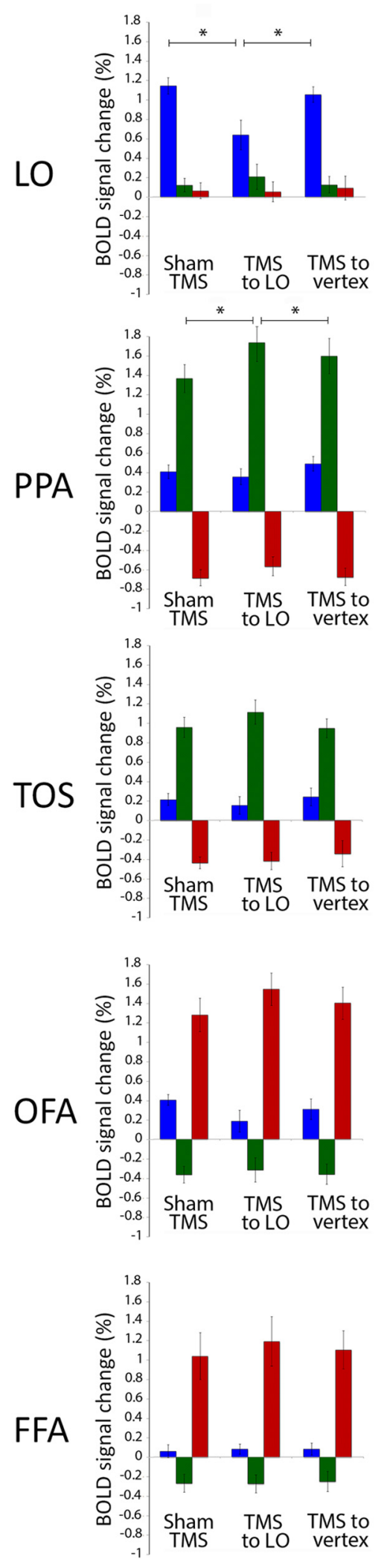

Right Hemisphere
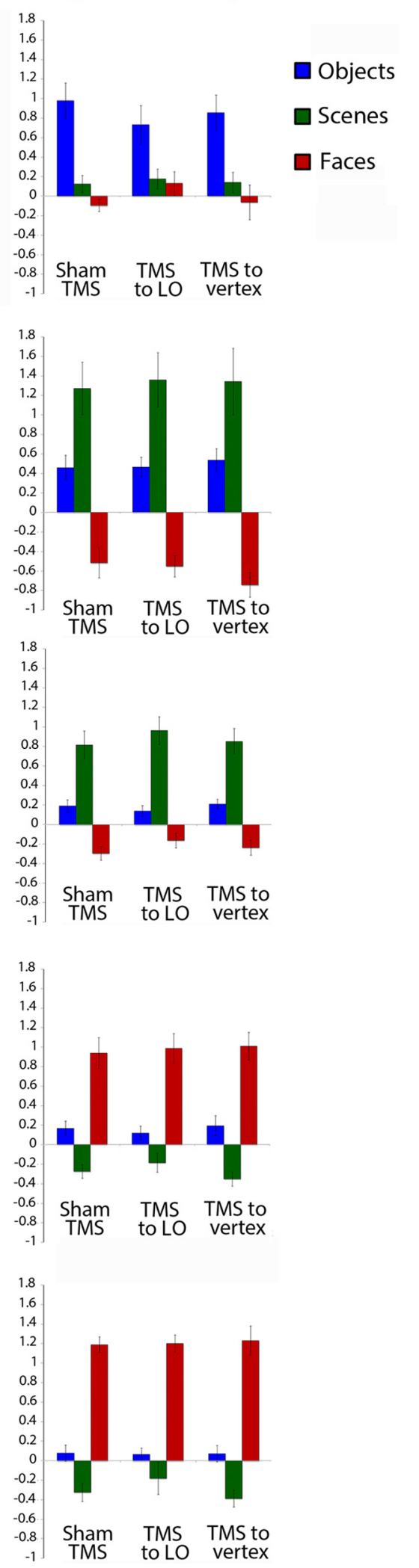

Figure 3. Percent $B O L D$ signal change across the sham, left $L 0$, and vertex stimulation conditions for each image category at each of the ROls in both hemispheres averaged across all participants. *Significant difference between stimulation conditions at $p<0.05$. and rTMS to left LO) revealed a significant positive correlation $\left(r^{2}=0.917\right.$, one-tailed $p<0.05)$. A Pearson's correlation between the BOLD response in the scene-selective left PPA and behavioral performance on the scene categorization task at the three-stimulation conditions revealed a significant positive correlation $\left(r^{2}=0.904\right.$, one-tailed $p<0.05$ ). These results support the notion that rTMS-induced changes in object- and scene-selective BOLD response are similarly reflected in behavioral performance on object- and scene-processing tasks.

\section{Discussion}

As a means of investigating the relationship between object- and scene-processing regions in the ventral visual cortex, we applied rTMS to the object-selective left LO and monitored consequent changes in BOLD signal in several ROIs.

After rTMS to left LO, we observed a significant decrease in BOLD response at the stimulation site while participants viewed objects, which was accompanied by a significant increase in BOLD response at the left PPA after rTMS to the left LO while viewing scenes. This finding suggests a functional interaction between these remote but interconnected brain regions. Although decrements in BOLD signal at the stimulation site have been demonstrated previously using an offline rTMS protocol (Sack et al., 2007; Andoh and Paus, 2011), TMS has been shown to affect distinct brain regions differentially when using the same protocol (excitement in some cases and inhibition in others; Pascual-et al., 2000). The current finding demonstrates specifically how area LO was affected by prolonged physiological disruption due to rTMS. In addition, the effects of rTMS to left LO on behavioral measures from our previous study were highly correlated with the changes in BOLD response observed in the present study.

One interpretation of these findings might be that the increased BOLD signal in the PPA is a compensation for the loss of object processing in LO. This idea is supported by recent research showing that the PPA may be specialized for certain types of objects as well as scenes (Troiani et al., 2012; Baldassano et al., 2013; Harel et al., 2013). Perhaps when LO is compromised through TMS, the PPA also assumes the responsibility of object processing. However, if the current increase in scene-selective BOLD signal at the left PPA was due to such a form of compensatory object processing, we might expect to see an increase in the non- 
preferred object-selective response in the PPA. We did not observe this effect, which refutes this interpretation. Any consequent BOLD signal changes after TMS to LO are restricted to each region's preferred image category (i.e., objects for $\mathrm{LO}$ and scenes for PPA). Specifically, when the scene-selective BOLD signal increased in the PPA after TMS to left LO, the object- and face-selective BOLD signals in the PPA showed no change. The restriction of significant TMS effects to the preferred image category within a ROI is supported by other behavioral findings (Pitcher et al., 2009) and event-related potentials (Sadeh et al., 2011). However, it is possible that the current methods are not sufficiently sensitive to reveal BOLD signal compensation across category selectivity. A more sophisticated analysis technique such as multivoxel pattern analysis could potentially reveal the interplay between object and scene information within the PPA during TMS to LO.

No significant changes were observed in the scene-selective left TOS between the three stimulation conditions despite its recently discovered causal role in the scene perception network (Dilks et al., 2013; Ganaden et al., 2013). Less is known about the TOS and its role in scene processing compared with its counterpart in the scene-selective network, the PPA. In addition, the TOS is less reliably localized using fMRI (Amit et al., 2012; Konkle and Oliva, 2012), as is evident from the present study in which only eight of nine participants showed a scene-selective response in the TOS (Table 1). Perhaps the inconsistency in localizing this region could be partly responsible for the lack of effect observed here. An equally likely explanation could be that the TOS does not share the same form of connectivity with area LO as does the PPA. Although the TOS has been implicated in perceiving scenes that do not contain obvious objects (Grill-Spector, 2003), its response properties differ significantly from those of the PPA (MacEvoy and Epstein, 2007), which may suggest different connectivity requirements between these two regions and area LO and different roles in the scene-processing network.

Although previous research has demonstrated anatomical connectivity between area LO and the OFA (Kim et al., 2006), we failed to observe significant changes in selectivity to faces in the left OFA or the left FFA when rTMS was applied to left LO. Despite these known anatomical connections, the present findings are supported by behavioral data demonstrating that rTMS to the OFA affects processing of faces and face parts but that rTMS to LO does not show this same behavioral disruption when viewing face stimuli (Pitcher et al., 2007).

No significant differences between stimulation conditions were observed for any of the ROIs in the hemisphere contralateral to stimulation. Although interhemispheric effects of rTMS have been reported previously (Bohning et al., 2000; Bestmann et al., 2008; Blankenburg et al., 2008), the present findings show that the remote effects of rTMS to left LO do not demonstrate any transcallosal influences.

Recent investigations into the scene perception network have revealed a stronger link between object-selective LO and sceneselective PPA (Troiani et al., 2012; Baldassano et al., 2013; Harel et al., 2013) and have even suggested that LO might constitute a separate object-based channel for scene recognition (MacEvoy and Epstein, 2011). The current finding of rTMS-induced disruption to LO leading to an increase in activity in the PPA is consistent with the view that these two regions share a functional connection. Although patient work demonstrates that the representation of a scene is not strictly built up through a hierarchy of individual object representation, it is clear that these potentially parallel pathways for object and scene information share an in- terdependent relationship. Behavioral studies have demonstrated that scene context can facilitate the identification of objects (Boyce and Pollatsek, 1992; Rayner and Pollatsek, 1992; Bar, 2004) and contextual categorization of scenes can be impaired by the presence of a salient object, particularly when the object is incongruent with the scene context (Joubert et al., 2007). The reciprocal relationship between the decrease in $\mathrm{BOLD}$ response at the left $\mathrm{LO}$ to objects and increase in BOLD response at the left PPA to scenes suggest a release of inhibitory connections between these two parallel pathways.

\section{Conclusion}

We have demonstrated that applying rTMS to one region, the left LO, can affect activity in a specific remote cortical area, the left PPA, but not other regions such as the OFA and the FFA. This supports the view that rTMS may influence interconnected brain regions not just diffusely but also via specific functional tracts. The distinction between these local and remote effects of rTMS may help to clarify the debate concerning the modular or distributed nature of systems comprising the ventral visual cortex. Traditionally, studies using TMS have provided evidence for functional specialization of specific brain regions or "modules"; however, we show here that influencing a cortical site selective for objects with rTMS can have opposite effects on a scene-selective region, confirming a network of pathways with possible inhibitory connections supporting the perception of scenes.

\section{References}

Amit E, Mehoudar E, Trope Y, Yovel G (2012) Do object-category selective regions in the ventral visual stream represent perceived distance information? Brain Cogn 80:201-213. CrossRef Medline

Andoh J, Paus T (2011) Combining functional neuroimaging with off-line brain stimulation: modulation of task-related activity in language areas. J Cogn Neurosci 23:349-361. CrossRef Medline

Baldassano C, Beck DM, Fei-Fei L (2013) Differential connectivity within the parahippocampal place area. Neuroimage 75:228-237. CrossRef Medline

Bar M (2004) Visual objects in context. Nat Rev Neurosci 5:617-629. CrossRef Medline

Bestmann S, Swayne O, Blankenburg F, Ruff CC, Haggard P, Weiskopf N, Josephs O, Driver J, Rothwell JC, Ward NS (2008) Dorsal premotor cortex exerts state-dependent causal influences on activity in contralateral primary motor and dorsal premotor cortex. Cereb Cortex 18:1281-1291. CrossRef Medline

Biederman, I. (1981) On the semantics of a glance at a scene. In: Perceptual organization (Kubovy M, Pomerantz J, eds), pp 213-263. Hillsdale, NJ: Lawrence Erlbaum Associates.

Biederman I (1987) Recognition-by-components: a theory of human image understanding. Psychol Rev 94:115-147. CrossRef Medline

Blankenburg F, Ruff CC, Bestmann S, Bjoertomt O, Eshel N, Josephs O, Weiskopf N, Driver J (2008) Interhemispheric effect of parietal TMS on somatosensory response confirmed directly with concurrent TMS-fMRI. J Neurosci 28:13202-13208. CrossRef Medline

Bohning DE, Shastri A, Wassermann EM, Ziemann U, Lorberbaum JP, Nahas Z, Lomarev MP, George MS (2000) BOLD-f MRI response to singlepulse transcranial magnetic stimulation (TMS). J Magn Reson Imaging 11:569-574. CrossRef Medline

Boyce SJ, Pollatsek A (1992) Identification of objects in scenes: the role of scene background in object naming. J Exp Psychol Learn Mem Cogn 18:531-543. CrossRef Medline

Brodeur MB, Dionne-Dostie E, Montreuil T, Lepage M (2010) The Bank of Standardized Stimuli (BOSS), a new set of 480 normative photos of objects to be used as visual stimuli in cognitive research. PLoS One 5:e10773. CrossRef Medline

Campana G, Cowey A, Walsh V (2002) Priming of motion direction and area V5/MT: a test of perceptual memory. Cereb Cortex 12:663-669. CrossRef Medline

Chen R, Classen J, Gerloff C, Celnik P, Wassermann EM, Hallett M, Cohen 
LG (1997) Depression of motor cortex excitability by low-frequency transcranial magnetic stimulation. Neurology 48:1398-1403. CrossRef Medline

De Graef P, Christaens D, d'Ydewalle G (1990) Perceptual effects of scene context on object identification. Psychol Res 52:317-329. CrossRef Medline

Dilks DD, Julian JB, Paunov AM, Kanwisher N (2013) The occipital place area is causally and selectively involved in scene perception. J Neurosci 33:1331-1336a. CrossRef Medline

Epstein R, Kanwisher N (1998) A cortical representation of the local visual environment. Nature 392:598-601. CrossRef Medline

Ferreri F, Pasqualetti P, Määttä S, Ponzo D, Ferrarelli F, Tononi G, Mervaala E, Miniussi C, Rossini PM (2011) Human brain connectivity during single and paired pulse transcranial magnetic stimulation. Neuroimage 54:90-102. CrossRef Medline

Friedman A (1979) Framing pictures: the role of knowledge in automatized encoding and memory for gist. J Exp Psychol Gen 108:316-355. CrossRef Medline

Ganaden RE, Mullin CR, Steeves JK (2013) Transcranial magnetic stimulation to the transverse occipital sulcus affects scene but not object processing. J Cogn Neurosci 25:961-968. CrossRef Medline

Gauthier I, Tarr MJ, Moylan J, Skudlarski P, Gore JC, Anderson AW (2000) The fusiform "face area" is part of a network that processes faces at the individual level. J Cogn Neurosci 12:495-504. CrossRef Medline

Golomb JD, Albrecht AR, Park S, Chun MM (2011) Eye movements help link different views in scene-selective cortex. Cereb Cortex 21:2094-2102. CrossRef Medline

Grill-Spector K (2003) The neural basis of object perception. Curr Opin Neurobiol 13:159-166. CrossRef Medline

Grill-Spector K, Malach R (2004) The human visual cortex. Annu Rev Neurosci 27:649-677. CrossRef Medline

Grill-Spector K, Kourtzi Z, Kanwisher N (2001) The lateral occipital complex and its role in object recognition. Vision Res 41:1409-1422. CrossRef Medline

Harel A, Kravitz DJ, Baker CI (2013) Deconstructing visual scenes in cortex: gradients of object and spatial layout information. Cereb Cortex 23:947957. CrossRef Medline

Joubert OR, Rousselet GA, Fize D, Fabre-Thorpe M (2007) Processing scene context: fast categorization and object interference. Vision Res 47:32863297. CrossRef Medline

Kanwisher N, McDermott J, Chun MM (1997) The fusiform face area: a module in human extrastriate cortex specialized for face perception. J Neurosci 17:4302-4311. Medline

Kim M, Ducros M, Carlson T, Ronen I, He S, Ugurbil K, Kim DS. (2006) Anatomical correlates of the functional organization in the human occipitotemporal cortex. Magn Reson Imaging 24:583-590. CrossRef Medline

Konkle T, Oliva A (2012) A real-world size organization of object responses in occipitotemporal cortex. Neuron 74:1114-1124. CrossRef Medline

MacEvoy SP, Epstein RA (2007) Position selectivity in scene- and objectresponsive occipitotemporal regions. J Neurophysiol 98:2089-2098. CrossRef Medline

MacEvoy SP, Epstein RA (2011) Constructing scenes from objects in human occipitotemporal cortex. Nat Neurosci 14:1323-1329. CrossRef Medline

Malach R, Reppas JB, Benson RR, Kwong KK, Jiang H, Kennedy WA, Ledden PJ, Brady TJ, Rosen BR, Tootell RB. (1995) Object-related activity revealed by functional magnetic resonance imaging in human occipital cortex. Proc Natl Acad Sci U S A 92:8135-8139. CrossRef Medline

Mullin CR, Steeves JK (2011) TMS to the lateral occipital cortex disrupts object processing but facilitates scene processing. J Cogn Neurosci 23: 4174-4184. CrossRef Medline
Pascual-Leone A, Tormos JM, Keenan J, Tarazona F, Cañete C, Catalá MD (1998) Study and modulation of human cortical excitability with transcranial magnetic stimulation. J Clin Neurophysiol 15:333-343. CrossRef Medline

Pascual-Leone, A., Walsh, V, Rothwell J (2000) Transcranial magnetic stimulation in cognitive neuroscience-virtual lesion, chronometry, and functional connectivity. Curr Opin Neurobiol 10:232-237. CrossRef Medline

Pitcher D, Walsh V, Yovel G, Duchaine B (2007) TMS evidence for the involvement of the right occipital face area in early face processing. Curr Biol 17:1568-1573. CrossRef Medline

Pitcher D, Charles L, Devlin JT, Walsh V, Duchaine B (2009) Triple dissociation of faces, bodies and objects in the extrastriate cortex. Curr Biol 19:319-324. CrossRef Medline

Rayner K, Pollatsek A (1992) Eye movements and scene perception. Can J Psychol 46:342-376. CrossRef Medline

Rossi S, Hallett M, Rossini PM, Pascual-Leone A, Pascual-Leone A; Safety of TMS Consensus Group (2009) Safety, ethical considerations, and application guidelines for the use of transcranial magnetic stimulation in clinical practice and research. Clin Neurophysiol 120:2008-2039. CrossRef Medline

Ruff CC, Driver J, Bestmann S (2009) Combining TMS and fMRI: From 'virtual lesions' to functional-network accounts of cognition. Cortex 45: 1043-1049. CrossRef Medline

Sack AT, Kohler A, Bestmann S, Linden DE, Dechent P, Goebel R, Baudewig J. (2007) Imaging the brain activity changes underlying impaired visuospatial judgments: simultaneous FMRI, TMS, and behavioral studies. Cereb Cortex 17:2841-2852. CrossRef Medline

Sadeh B, Pitcher D, Brandman T, Eisen A, Thaler A, Yovel G (2011) Stimulation of category-selective brain areas modulates ERP to their preferred categories. Curr Biol 21:1894-1899. CrossRef Medline

Sergent J, Ohta S, MacDonald B (1992) Functional neuroanatomy of face and object processing A positron emission tomography study. Brain 115: 15-36. CrossRef Medline

Siebner HR, Bergmann TO, Bestmann S, Massimini M, Johansen-Berg H, Mochizuki H, Bohning DE, Boorman ED, Groppa S, Miniussi C, PascualLeone A, Huber R, Taylor PC, Ilmoniemi RJ, De Gennaro L, Strafella AP, Kähkönen S, Klöppel S, Frisoni GB, George MS, et al. (2009) Consensus paper: combining transcranial stimulation with neuroimaging. Brain Stimul 2:58-80. CrossRef Medline

Silvanto J, Lavie N, Walsh V (2005) Double dissociation of V1 and V5/MT activity in visual awareness. Cereb Cortex 15:1736-1741. CrossRef Medline

Steeves JK, Humphrey GK, Culham JC, Menon RS, Milner AD, Goodale MA (2004) Behavioral and neuroimaging evidence for a contribution of color and texture information to scene classification in a patient with visual form agnosia. J Cogn Neurosci 16:955-965. CrossRef Medline

Steeves JK, Culham JC, Duchaine BC, Pratesi CC, Valyear KF, Schindler I, Humphrey GK, Milner AD, Goodale MA (2006) The fusiform face area is not sufficient for face recognition: evidence from a patient with dense prosopagnosia and no occipital face area. Neuropsychologica 44:594609. CrossRef Medline

Troiani V, Stigliani A, Smith ME, Epstein RA (2012) Multiple object properties drive scene-selective regions. Cereb Cortex. Advance online publication. doi:10.1093/cercor/bhs364. CrossRef Medline

Wassermann EM (1998) Risk and safety of repetitive transcranial magnetic stimulation: Report and suggested guidelines from the International Workshop on the Safety of Repetitive Transcranial Magnetic Stimulation, June 5-7, 1996. Electroencephalogr Clin Neurophysiol 108:1-16. CrossRef Medline 